\title{
Design of an Improved Fuzzy Logic based Control System for Washing Machines
}

\author{
Ankur Agarwal \\ M.Tech Scholar \\ Department of Computer \\ Science and Engineering \\ Radharaman Engineering \\ College, Bhopal (M.P.)
}

\author{
Ankur Mishra \\ Assistant Professor \\ Department of Computer \\ Science and Engineering \\ Radharaman Engineering \\ College, Bhopal (M.P.)
}

\author{
Mukesh Dixit \\ Head of Department \\ Department of Computer \\ Science and Engineering \\ Radharaman Engineering \\ College, Bhopal (M.P.)
}

\begin{abstract}
Laundry is an essential part of people's daily life. Good washing machine can not only save energy, but also carry on a more reasonable washing to the clothes to prolong its service life. Automatic washing machine frees the user's hands, so that the user can better allocate the time to do other work, so as to improve the work efficiency. Therefore, a fuzzy logic controller (FLC) based washing machine needs to be designed. This paper presents an improved fuzzy logic based control system for washing machines. The simulation results show that the system has a shorter washing time.
\end{abstract}

\section{Keywords}

Defuzzification, FIS, FLC, Fuzzy Rules, Washing Time.

\section{INTRODUCTION}

Washing machines are one in every of the foremost common home appliances found these days. The essence of such a machine is to cut back the labor and effectively offer cleaner garments. To prove the cleanliness of garments, the washing machine makers are motivated towards a fully automatic sensing element operated machines which may completely sense the quantity of wash load, the quantity of dirtiness of the garments and also the style of material within the current wash cycle to directly predict the wash time needed. The wash sensing element may be an easy optical sensing element employed to determine the physical measure of light, passed through a glass tube, which may then be reborn to electrical signals to predict the quantity of dirtiness. Therefore, a fuzzy logic controller (FLC) based washing machine needs to be designed.

Theory of sets is one in all the vital tools in modern mathematics. A may be a collection of comparable form of distinct objects called the component of the set. Once some category is created like "class of high priced cars" some ambiguity, inexactitude or unclearness arises when making a decision whether or not an element belongs to a class. In such form of categories associate object need not belong to a category there is also a degree of belongingness. There comes the idea of fuzzy sets that was introduced by Lotfi A. Zadeh [1]. Fuzzy sets are also viewed as associate extension of crisp sets as they permit the partial membership that is not promising within the crisp sets. The membership of an element in a fuzzy set doesn't need being complete, that's any component of a fuzzy set may also be member of another fuzzy set within the same universe. In fuzzy sets there are not any sharp boundaries as there's some unclearness exist within the data. The degree of membership for fuzzy sets is between zero (0) and one (1).

\section{LITERATURE SURVEY}

In 1965 , the conception of fuzzy logic was initially visualized by Professor Lofti A. Zadeh [1]. Fuzzy logic is a conception that helps computers in making selections in an exceedingly means that resembles human behaviors. It assists trade in increasing productivity, makes the chance for the production to be additional convenient and most significantly it helps industries in economical terms. This concept had been given in one amongst his research papers under the name Fuzzy logic or Fuzzy sets [1]. It is employed to observe nonlinear systems that are complicated to deal mathematically. The non-probabilistic, uncertainties problems are observed by fuzzy logic and fuzzy set theory [2]. It is powerful design philosophy for describing and developing control systems that provides straightforward and spontaneous method for design engineers to implement advanced systems [3]. Fuzzy Controllers, [4] as contrary to classical controllers are able to utilize knowledge elicited from human decisions or human operators. Fuzzy Logic Controller for Gas Heater was designed using behavioral modeling. These modules are then connected via structural VHDL to manage valve angle [5]. The fuzzy logic controller for Liquid Level Control was designed using MATLAB for managing valve. It is compared with the PID controller. In 2007, the Fuzzy Inference is employed for determining wash time using triangular membership function [6].

In 2011, Manish Aggarwal presented the Fuzzy Logic Control for Washing Machine. It has 2 inputs named 'Type of Dirt' and 'Degree of Dirt'. The output was in the form of wash time with the inference engine that offers 9 rules for the FLC [7]. In 2009, Pritesh Lohani suggested an improved controller microchip which consists of 3 inputs i.e. Types of Dirt, Dirtiness of Clothes and Mass of Clothes. The output of the

controller is Wash Time with 25 rules [8]. In 1974, the primary fuzzy logic based control experiment was done by Mamdani [9]. The author designed the fuzzy logic for a steam engine. After 1980, the use of fuzzy logic based control system becomes common in washing machines, metro, vacuum cleaners, elevators and company operations. Advancements in engineering in recent years have permitted fuzzy logic to be utilized in numerous fields [10]. Today, fuzzy logic has found its application in many fields like home electronics, automotive industries, electronic control systems, breaking systems, etc [11]. Alhanjouri and Alhaddad's washing machine takes two input variables (dirt type and degree of dirtiness) to obtain wash time as the output [12]. On the basis of fuzzy logic, neural network and its learning algorithm, the washing machine fuzzy controller is proposed $[13,14]$. Kumar and Haider decide to diminish the washing time by selecting dirtiness and quantity as input [15]. To 
obtain the controller output, a Sugeno type FLC structure has been provided [16]. The design and implementation of an autonomous room air cooler using fuzzy rule based control system for the actuators; cooler fan, water pump and room exhaust fan. Three defuzzifiers are used to control and MATLAB-simulation is used to achieve the designed goal [17].

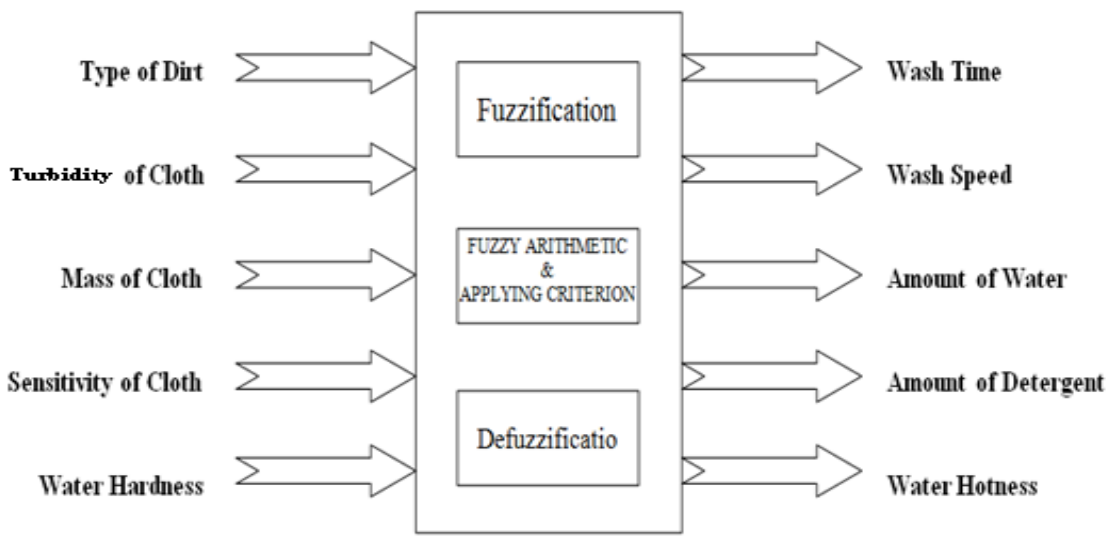

Fig. 1. Proposed FLC

\section{PROPOSED DESIGN FOR FUZZY LOGIC MODELING OF WASHING MACHINE}

Fuzzy logic is best applied in fields where a great amount of uncertainty or fuzziness exists. In our case, building an expert system by applying fuzzy inference rules is a very suitable choice. In a fuzzy inference system or FIS, fuzzy set theory is applied to map inputs (or attributes) to outputs. The fuzzification process involves transforming crisp values into various grades of membership for linguistic terms of fuzzy sets. Membership functions are used to associate a grade to each and every linguistic variable. In our study, we implement the Mamdani system that is depicted in Figure 1 and centroid as defuzzification method.

After we introduce our five input variables and five output variables as below, we determine membership functions for each variable for our fuzzy system and their corresponding fuzzy memberships as presented in Figure 2 and Figure 3 respectively.

Input Parameters:

1. Type of Dirt

2. Turbidity of Cloth

3. Mass of Cloth

4. Sensitivity of Cloth

5. Water Hardness

\section{Output Parameters:}

1. Wash Time

2. Wash Speed

3. Amount of Water

4. Amount of Detergent

5. Water Hotness
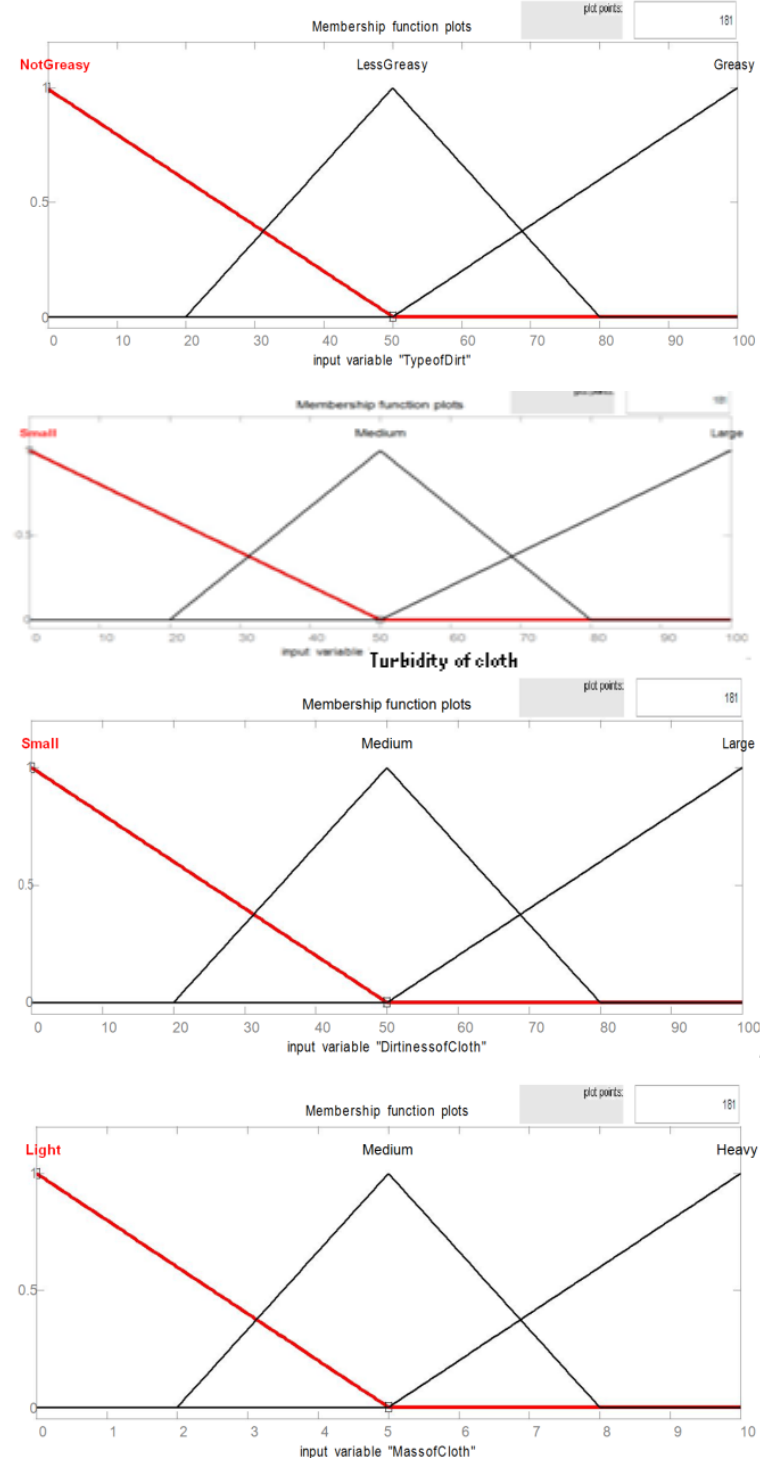


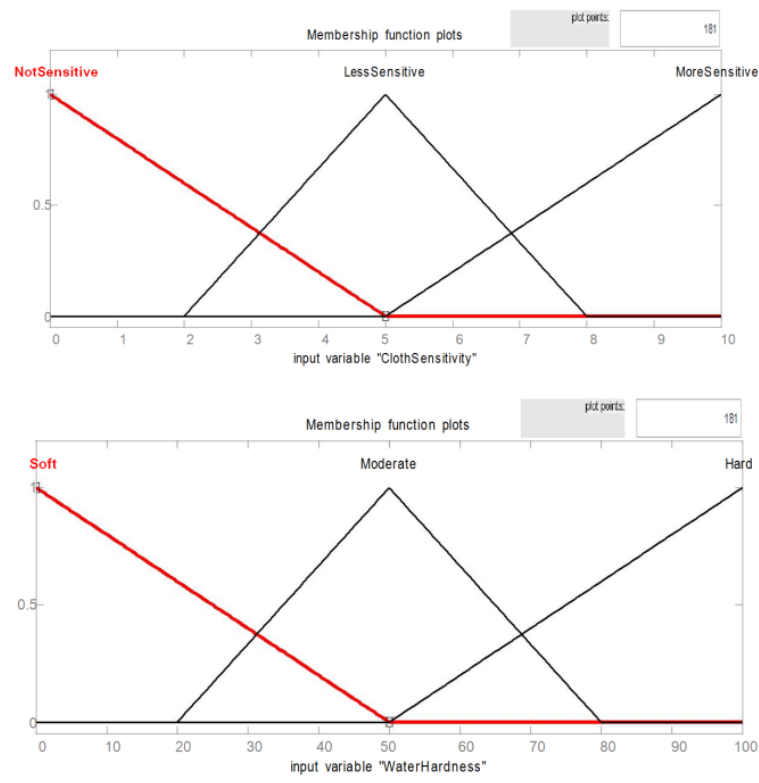

Fig. 2. Fuzzy logic input membership function
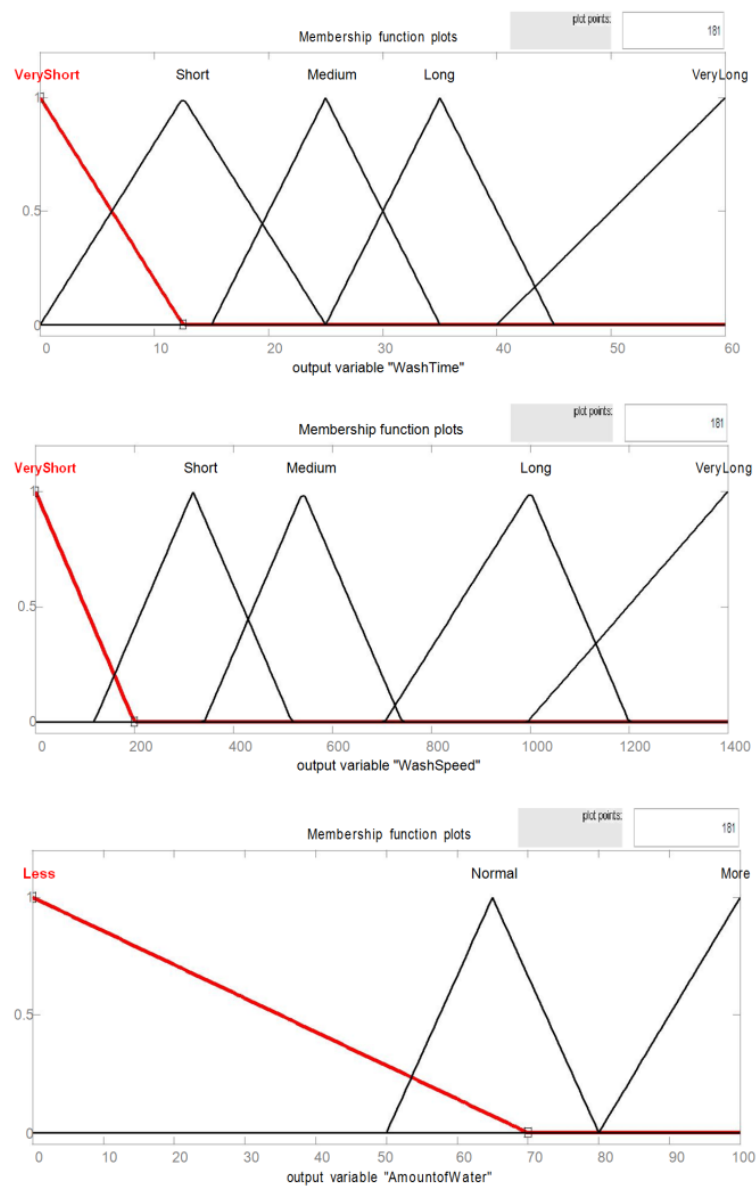
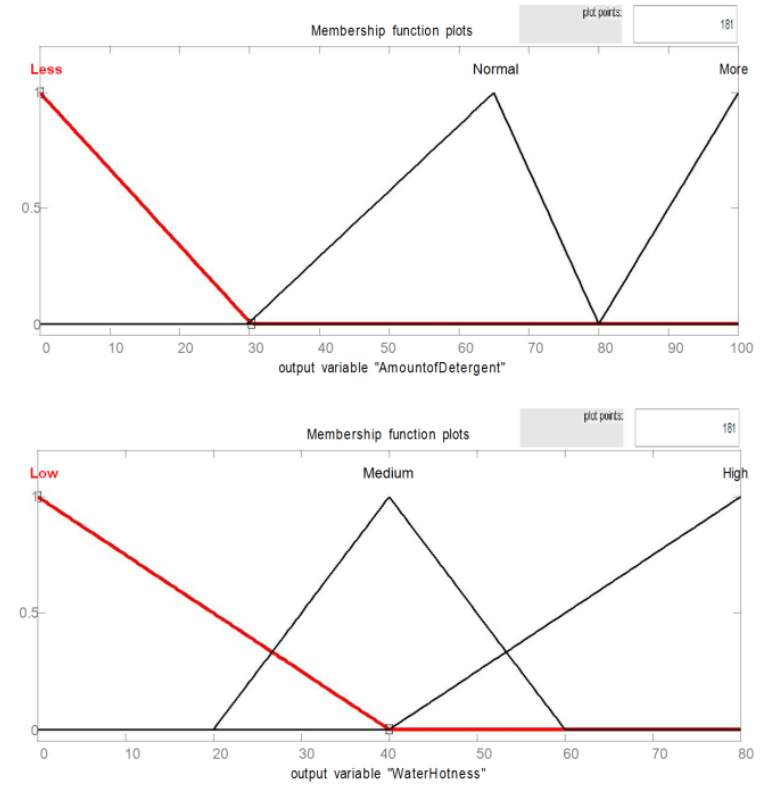

Fig. 3. Fuzzy logic output membership function

In order to apply fuzzy logic to washing machine, it is necessary to establish fuzzy logic rules., After determining the membership functions, a total of 27 rules have been established for defining relationship among the parameters. The rules obtained can be read in terms of IF and THEN statements as shown in below.

\section{Fuzzy Rules:}

\section{Rule 1}

If (TypeofDirt is Greasy) or (Turbidity of cloth is Large) or (MassofCloth is Heavy) or (SensitivityofCloth is MoreSensitive) or (WaterHardness is Hard) then (WashTime is Long)(WashSpeed is Medium)(AmountofWater is Normal)(AmountofDetergent is Normal)(WaterHotness is Medium) (1)

\section{Rule 2}

If (TypeofDirt is NotGreasy) and (Turbidity of cloth is Small) and (MassofCloth is Light) and (SensitivityofCloth is NotSensitive) and (WaterHardness is Soft) then (WashTime is VeryShort)(WashSpeed is VeryShort)(AmountofWater is Less)(AmountofDetergent is Less)(WaterHotness is Low) (1)

\section{Rule 3}

If (TypeofDirt is LessGreasy) and (Turbidity of cloth is Medium) and (MassofCloth is Medium) and (SensitivityofCloth is LessSensitive) and (WaterHardness is Moderate) then (WashTime is Medium)(WashSpeed is Medium)(AmountofWater is Normal)(AmountofDetergent is Normal)(WaterHotness is Medium) (1)

\section{Rule 4}

If (TypeofDirt is NotGreasy) or (Turbidity of cloth is Small) or (MassofCloth is Light) or (SensitivityofCloth is NotSensitive) or (WaterHardness is Soft) then (WashTime is Short)(WashSpeed is Medium)(AmountofWater is Normal)(AmountofDetergent is Normal)(WaterHotness is Low) (1) 


\section{Rule 5}

If (TypeofDirt is Greasy) and (Turbidity of cloth is Large) and (MassofCloth is Heavy) and (SensitivityofCloth is MoreSensitive) and (WaterHardness is Hard) then (WashTime is VeryLong)(WashSpeed is VeryLong)(AmountofWater is More)(AmountofDetergent is More)(WaterHotness is High) (1)

\section{Rule 6}

If (TypeofDirt is NotGreasy) and (Turbidity of cloth is Small) and (MassofCloth is Light) and (SensitivityofCloth is NotSensitive) and (WaterHardness is Moderate) then (WashTime is VeryShort)(WashSpeed is VeryShort)(AmountofWater is Less)(AmountofDetergent is Less)(WaterHotness is Low) (1)

\section{Rule 7}

If (TypeofDirt is NotGreasy) and (Turbidity of cloth is Small) and (MassofCloth is Light) and (SensitivityofCloth is NotSensitive) and (WaterHardness is Hard) then (WashTime is VeryShort)(WashSpeed is Short)(AmountofWater is Less)(AmountofDetergent is Less)(WaterHotness is Low) (1)

\section{Rule 8}

If (TypeofDirt is NotGreasy) and (Turbidity of cloth is Small) and (MassofCloth is Light) and (SensitivityofCloth is LessSensitive) and (WaterHardness is Soft) then (WashTime is VeryShort)(WashSpeed is VeryShort)(AmountofWater is Less)(AmountofDetergent is Less)(WaterHotness is Low) (1)

\section{Rule 9}

If (TypeofDirt is NotGreasy) and (Turbidity of cloth is Small) and (MassofCloth is Light) and (SensitivityofCloth is LessSensitive) and (WaterHardness is Moderate) then (WashTime is VeryShort)(WashSpeed is VeryShort)(AmountofWater is Less)(AmountofDetergent is Less)(WaterHotness is Low) (1)

\section{Rule 10}

If (TypeofDirt is NotGreasy) and (Turbidity of cloth is Small) and (MassofCloth is Light) and (SensitivityofCloth is LessSensitive) and (WaterHardness is Hard) then (WashTime is Short)(WashSpeed is Short)(AmountofWater is Less)(AmountofDetergent is Less)(WaterHotness is Low) (1)

\section{Rule 11}

If (TypeofDirt is NotGreasy) and (Turbidity of cloth is Small) and (MassofCloth is Light) and (SensitivityofCloth is MoreSensitive) and (WaterHardness is Soft) then (WashTime is VeryShort)(WashSpeed is VeryShort)(AmountofWater is Less)(AmountofDetergent is Less)(WaterHotness is Low) (1)

\section{Rule 12}

If (TypeofDirt is NotGreasy) and (Turbidity of cloth is Small) and (MassofCloth is Light) and (SensitivityofCloth is MoreSensitive) and (WaterHardness is Moderate) then (WashTime is Short)(WashSpeed is Short)(AmountofWater is Less)(AmountofDetergent is Less)(WaterHotness is Low) (1)

\section{Rule 13}

If (TypeofDirt is NotGreasy) and (Turbidity of cloth is Small) and (MassofCloth is Light) and (SensitivityofCloth is MoreSensitive) and (WaterHardness is Hard) then (WashTime is Short)(WashSpeed is Medium)(AmountofWater is Less)(AmountofDetergent is Normal)(WaterHotness is Medium) (1)

\section{Rule 14}

If (TypeofDirt is NotGreasy) and (Turbidity of cloth is Small) and (MassofCloth is Medium) and (SensitivityofCloth is LessSensitive) and (WaterHardness is Soft) then (WashTime is Short)(WashSpeed is Medium)(AmountofWater is Less)(AmountofDetergent is Normal)(WaterHotness is Medium) (1)

\section{Rule 15}

If (TypeofDirt is NotGreasy) and (Turbidity of cloth is Medium) and (MassofCloth is Medium) and (SensitivityofCloth is LessSensitive) and (WaterHardness is Moderate) then (WashTime is Medium)(WashSpeed is Long)(AmountofWater is Normal)(AmountofDetergent is Normal)(WaterHotness is Medium) (1)

\section{Rule 16}

If (TypeofDirt is LessGreasy) and (Turbidity of cloth is Medium) and (MassofCloth is Medium) and (SensitivityofCloth is LessSensitive) and (WaterHardness is Moderate) then (WashTime is Medium)(WashSpeed is Long)(AmountofWater is Normal)(AmountofDetergent is Normal)(WaterHotness is Medium) (1)

\section{Rule 17}

If (TypeofDirt is LessGreasy) and (Turbidity of cloth is Medium) and (MassofCloth is Heavy) and (SensitivityofCloth is LessSensitive) and (WaterHardness is Moderate) then (WashTime is Long)(WashSpeed is Long)(AmountofWater is More)(AmountofDetergent is More)(WaterHotness is High) (1)

\section{Rule 18}

If (TypeofDirt is Greasy) and (Turbidity of cloth is Medium) and (MassofCloth is Medium) and (SensitivityofCloth is MoreSensitive) and (WaterHardness is Hard) then (WashTime is Long)(WashSpeed is Long)(AmountofWater is More)(AmountofDetergent is More)(WaterHotness is High) (1)

\section{Rule 19}

If (TypeofDirt is Greasy) and (Turbidity of cloth is Medium) and (MassofCloth is Heavy) and (SensitivityofCloth is MoreSensitive) and (WaterHardness is Hard) then (WashTime is VeryLong)(WashSpeed is Long)(AmountofWater is More)(AmountofDetergent is More)(WaterHotness is High) (1)

\section{Rule 20}

If (TypeofDirt is Greasy) and (Turbidity of cloth is Large) and (MassofCloth is Medium) and (SensitivityofCloth is MoreSensitive) and (WaterHardness is Hard) then (WashTime is VeryLong)(WashSpeed is VeryLong)(AmountofWater is More)(AmountofDetergent is More)(WaterHotness is High) (1)

\section{Rule 21}

If (TypeofDirt is LessGreasy) and (Turbidity of cloth is Large) and (MassofCloth is Medium) and (SensitivityofCloth is LessSensitive) and (WaterHardness is Moderate) then (WashTime is Long)(WashSpeed is Long)(AmountofWater is More)(AmountofDetergent is More)(WaterHotness is High) (1)

Rule 22

If (TypeofDirt is Greasy) and (Turbidity of cloth is Small) and (MassofCloth is Heavy) and (SensitivityofCloth is LessSensitive) and (WaterHardness is Hard) then (WashTime is Long)(WashSpeed is Long)(AmountofWater is More)(AmountofDetergent is More)(WaterHotness is High) (1) 


\section{Rule 23}

If (TypeofDirt is Greasy) and (Turbidity of cloth is Large) and (MassofCloth is Light) and (SensitivityofCloth is LessSensitive) and (WaterHardness is Hard) then (WashTime is Long)(WashSpeed is Long)(AmountofWater is Normal)(AmountofDetergent is More)(WaterHotness is High) (1)

\section{Rule 24}

If (TypeofDirt is Greasy) and (Turbidity of cloth is Large) and (MassofCloth is Heavy) and (SensitivityofCloth is LessSensitive) and (WaterHardness is Soft) then (WashTime is Long)(WashSpeed is Long)(AmountofWater is Normal)(AmountofDetergent is More)(WaterHotness is High) (1)

\section{Rule 25}

If (TypeofDirt is LessGreasy) and (Turbidity of cloth is Small) and (MassofCloth is Light) and (SensitivityofCloth is NotSensitive) and (WaterHardness is Moderate) then (WashTime is VeryShort)(WashSpeed is VeryShort)(AmountofWater is Less)(AmountofDetergent is Less)(WaterHotness is Low) (1)

\section{Rule 26}

If (TypeofDirt is LessGreasy) and (Turbidity of cloth is Small) and (MassofCloth is Medium) and (SensitivityofCloth is LessSensitive) and (WaterHardness is Moderate) then (WashTime is Short)(WashSpeed is Medium)(AmountofWater is Normal)(AmountofDetergent is Normal)(WaterHotness is Low) (1)

\section{Rule 27}

If (TypeofDirt is LessGreasy) and (Turbidity of cloth is Small) and (MassofCloth is Heavy) and (SensitivityofCloth is LessSensitive) and (WaterHardness is Moderate) then (WashTime is Medium)(WashSpeed is Long)(AmountofWater is Normal)(AmountofDetergent is Normal)(WaterHotness is Medium) (1)

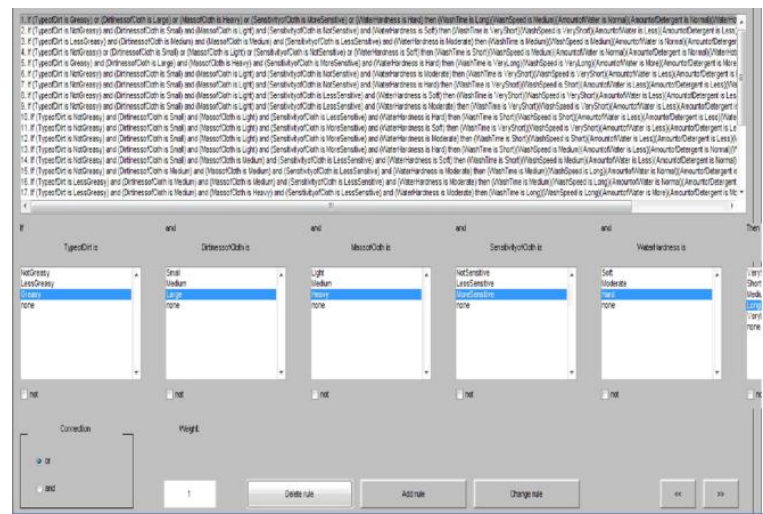

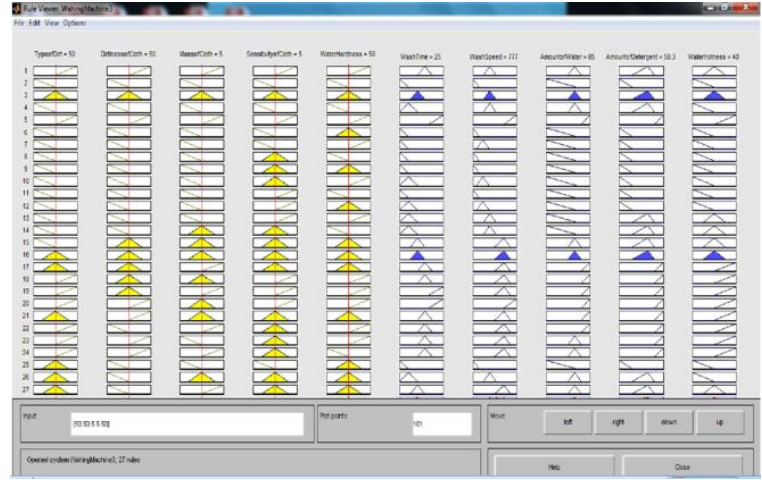

Fig. 4. Fuzzy logic rules and the output

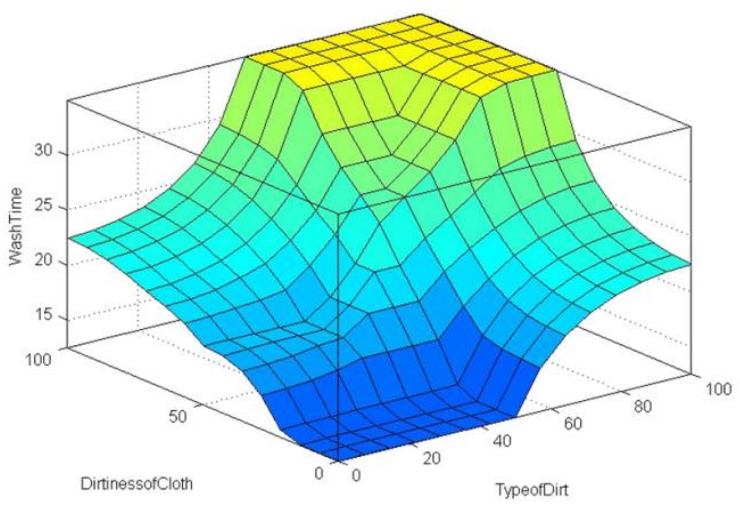

Fig. 5. Type of dirt and turbidity of cloth affects the wash time

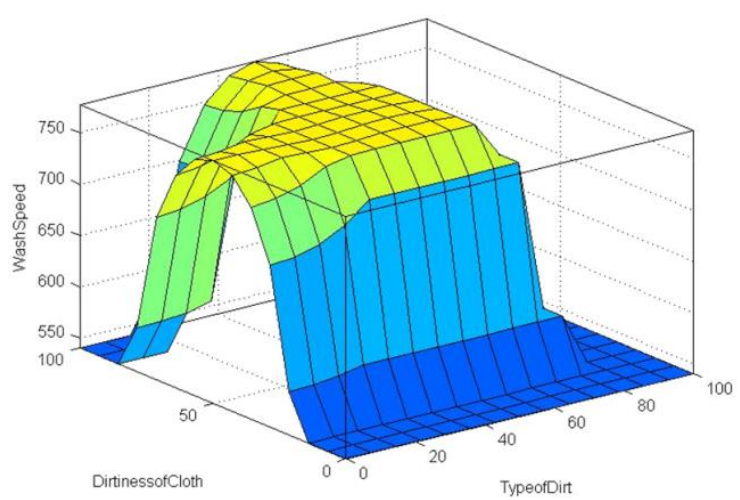

Fig. 6. Type of dirt and dirtiness of cloth affects the wash speed

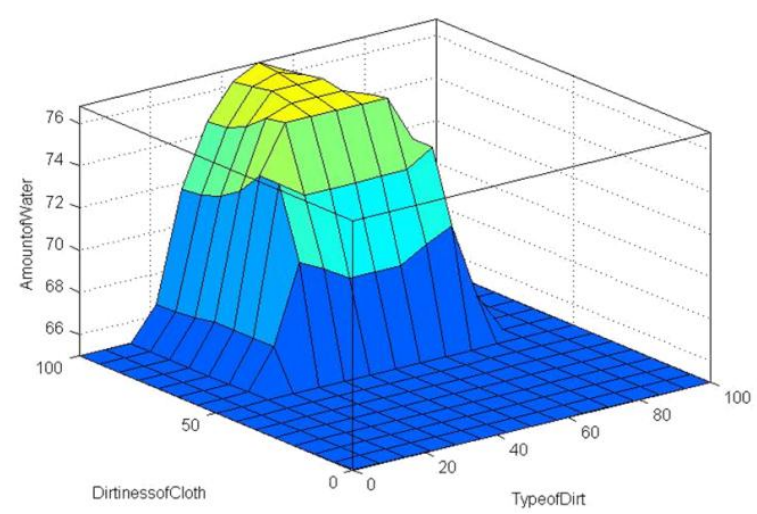

Fig. 7. Type of dirt and turbidity of cloth affects the amount of water 


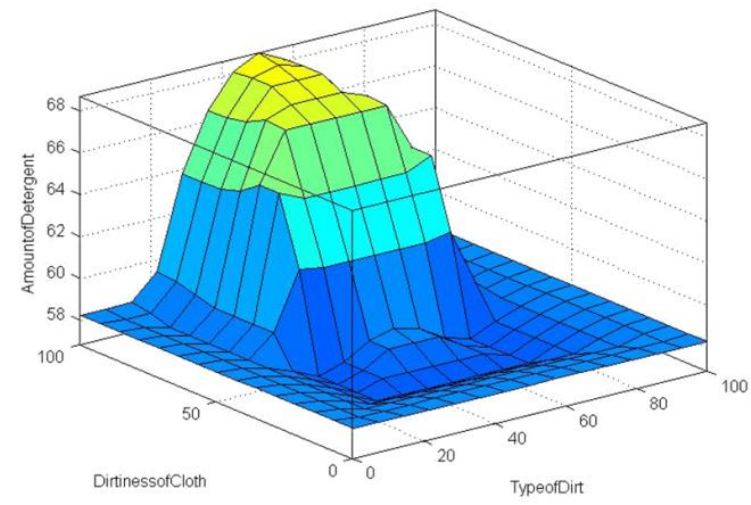

Fig. 8. Type of dirt and turbidity of cloth affects the amount of detergent

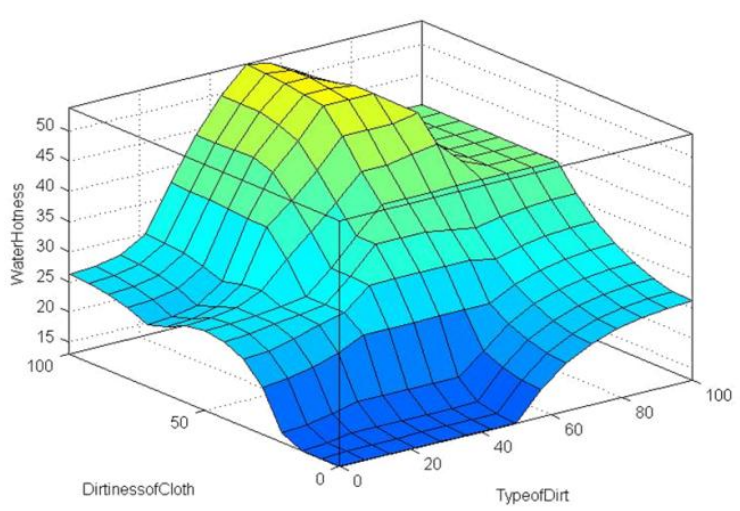

Fig. 9. Type of dirt and dirtiness of cloth affects the water hardness

The process of converting the fuzzy output is called defuzzification. This work uses centroid method for defuzzification. It can be expressed as

$$
\text { Wash Time } \quad \begin{aligned}
& =\bar{X}(\text { Centroid })=\frac{\sum_{1}^{60} x \mu(x)}{\sum_{1}^{60} \mu(x)} \\
& =\quad 25 \text { minutes. }
\end{aligned}
$$

\section{CONCLUSION}

This paper presents fuzzy logic controllers of Mamdani type. The results of this work reveal the way how a washing machine will respond in different conditions. As an example, if we take all input parameters values (Type of Dirt, Dirtiness of Cloth, Mass of Cloth, Sensitivity of Cloth and Water Hardness) as 50, the output parameter wash time is 25 minutes. MATLAB/Fuzzy logic toolbox is used to show this study.

\section{REFERENCES}

[1] L.A. Zadeh, Fuzzy Sets, Information and Control, 338353, (1965)

[2] Han H., Chun-Yi and Yury. S, Adaptive Control of a Class of Non-linear Systems with Non-Linearly Parameterized Fuzzy Approximation. IEEE Transactions on Fuzzy Systems, V01.9, No.2, 315-323, (2001)
[3] Workman, M. Hardware requirement for Fuzzy Logic Control Systems. Lubbock, TX: Texas Tech University, (1996)

[4] George J. Kilr and Bo Yuan, Fuzzy Sets and Fuzzy Logic (India: PHI, 1995)

[5] Sonia Chhabra , VHDL Implementation of Fuzzy Control System, (2006)

[6] Ge Zhe-Xue, Sun Zhi-Qiang. Neural N/w Theory and the realization MATLAB (Beijing: Electronics industry publishing, 2007)

[7] Manish Aggarwal, Fuzzy Logic Controller for Washing Machine, IIT Kharagpur (2011)

[8] Lohani P., and Hasan,S.R..Design of an Improved Controller Microchip For Washing Machine, $16^{\text {th }}$ Annual Electronics New Zealand Conference (pp. 2026).Dunedin : Otago University (2009)

[9] Mamdani, E.H., "Application of Fuzzy Algorithms for Control of Simple Dynamic Plant", Proc. IEEE, 121(12), 1585-1588, 1974.

[10] Şen Z., "Bulanık (Fuzzy) Mantık Ve Modelleme İlkeleri”, Bilge Sanat Yapım Yayınevi, İstanbul, 2001.

[11] Tiryaki, A.E., Kazan, R., "Bulasik Makinesinin Bulanik Mantik ile Nodellenmesi", Muhendis ve Makina Dergisi, Cilt:48, Sayi:565, Sakarya.

[12] Alhanjouri, M. and A. Alhaddad, A., "Optimize Wash Time of Washing Machine Using Fuzzy Logic", Islamic University of Gaza.

[13] Zhen. A. and Feng R. G., "The design of neural network fuzzy controller in washing machine," in Proc. 2012 International Conference on Computing, Measurement, Control and Sensor Network (CMCSN), Shanxi, China, 136-139, 2012.

[14] Virkhare N., Jasutkar R.W., Neuro-Fuzzy Controller Based Washing Machine, International Journal of Engineering Science Invention, 3(1), 48-51, 2014.

[15] Kumar D., Haider Y., Fuzzy Logic Based Control System for Washing Machines, International Journal of Computer Science and Technology, 4(2), 198-200, 2013.

[16] Mani Shankar Anand \& Barjeev Tyagi, Design and Implementation of Fuzzy Controller on FPGA, I.J. Intelligent Systems and Applications, 10, 35-42 Published Online in September MECS (www.mecs-press.org) (2012)

[17] M. Abbas, M. Saleem Khan, Fareeha Zafar, Autonomous Room Air Cooler Using Fuzzy Logic Control System, International Journal of Scientific \& Engineering Research Volume 2, Issue 5, (May-2011) 